\title{
How to Evaluate and Invest in Emerging A/E/C Technologies under Uncertainty
}

\author{
S. Ping Ho, A.M.ASCE, ${ }^{1}$ and Liang Y. Liu, M.ASCE ${ }^{2}$
}

\begin{abstract}
Many emerging architectural/engineering/construction (A/E/C) technology investments are of strategic importance and may create future growth opportunities. Therefore, from the strategic perspective, management needs a better method that can quantify the strategic value of technology investment and suggest optimal investment strategies when the future is uncertain. This paper presents a quantitative valuation method based on modern option pricing theory for evaluating major investments in emerging A/E/C technologies. This framework considers specifically the technology investment risk and embedded managerial options. It further aligns the investment evaluation process with the financial market. The analysis may help A/E/C firms more accurately evaluate investments in emerging technologies, such as information technology and automation, and make strategic investment decisions under uncertainty.
\end{abstract}

DOI: 10.1061/(ASCE)0733-9364(2003)129:1(16)

CE Database keywords: Construction management; Management methods; Technology; Risk management; Financial management.

\section{Introduction}

Advanced technologies are recognized as the main source of creating and improving the competitive advantages of a firm. The basis of international competition in construction is shifting from managerial to technological issues (Mitropoulos and Tatum 1999). Today, automation and robotics are recognized as the critical solutions to reducing cost, and to improving construction productivity, safety, and skilled labor shortage. By achieving these improvements, a construction firm could obtain not only direct cost savings but also competitive advantages that are crucial to the future growth of the firm. However, advanced technology and innovation typically involve significant capital investment. In many cases, it seems difficult to justify the investment in technology adoption. Warszawski and Navon (1998) point out some serious problems in evaluating a technology investment in the construction industry. For example, one major problem is that the indirect benefit and strategic benefit are difficult to measure. Moreover, except for those near-mature or mature technologies, most investment is characterized by the uncertainty of both the actual cost and benefit of a new technology, especially when the investment involves research and development (R\&D) activities. Managers in such cases may easily forego some investments that are risky or with low immediate return but highly valuable. As a great benefit to the business, a better methodology in the valuation process of investment in technology adoption may aid managers in making more effective decisions. This paper presents a

\footnotetext{
${ }^{1}$ Assistant Professor, Dept. of Civil Engineering, National Taiwan Univ., Taipei 10617, Taiwan. E-mail: spingho@ntu.edu.tw

${ }^{2}$ Associate Professor, Dept. of Civil and Environmental Engineering, Univ. of Illinois at Urbana-Champaign, Urbana, IL 61801. E-mail: lliu1@uiuc.edu

Note. Discussion open until July 1, 2003. Separate discussions must be submitted for individual papers. To extend the closing date by one month, a written request must be filed with the ASCE Managing Editor. The manuscript for this paper was submitted for review and possible publication on December 20, 2000; approved on February 26, 2002. This paper is part of the Journal of Construction Engineering and Management, Vol. 129, No. 1, February 1, 2003. CASCE, ISSN 0733-9364/ 2003/1-16-24/\$18.00.
}

quantitative valuation model based on modern option pricing theory in finance for evaluating investment in emerging architectural/engineering/construction (A/E/C) technologies. This model provides managers with an alternative to traditional capital budgeting techniques.

The paper is organized in four main parts. The first part provides an overview of traditional approaches to making technology investment decisions and their difficulties. Following is an introduction of the modern option pricing theory and why the theory can be the foundation of the model for technology investment. The third part presents an evaluation model for single-stage technology investment. The fourth part further derives an evaluation model for multistage technology investment. In the third and fourth parts, illustrative examples are given to demonstrate how the model can be utilized, and strategies for investing in emerging technologies are discussed.

\section{Rational Technology Adoption Selection and Quantitative Evaluation Methods}

Mitropoulos and Tatum (1999) argue that when the technological decisions are of company level and strategic importance, the decision making process should focus on gaining competitive advantages rather than saving costs. These decisions need more thorough, more quantitative and less intuitive analysis. This evaluation process can be called the "rational approach" (Mitropoulos and Tatum 1999) to technology selection. In this paper, we shall focus on those new technologies that are the core technologies of company level, and assume that the evaluation process is "rational" and quantitative. Aggarwal (1993) argues that many problems contribute to making the practice of evaluating the capital investment "closer to an art and farther from a science than is desirable." One purpose of this paper is to make the evaluation process of the emerging $\mathrm{A} / \mathrm{E} / \mathrm{C}$ technology investment closer to a science.

Trigeorgis (1996) points out some major drawbacks of traditional quantitative capital budgeting techniques such as payback period method, internal rate of return (IRR) and decision tree analysis. From the financial theoretic perspective, the net present 
value (NPV) approach is considered the only evaluation method that is consistent with a firm's objective of maximizing the stockholders' utilities (Copeland and Weston 1988). Thus, the NPV method is considered superior to other techniques, such as IRR, accounting rate of return, and payback period. However, the discount rate for obtaining NPV cannot be correctly determined when the management has managerial flexibilities. Ye and Tiong (2000) present the NPV-at-risk method to analyze the impact of the risks on an infrastructure investment. The basic concept of this method is to simulate those primary variables underlying a project's NPV and obtain the NPV's distribution and confidence level. Myers (1976) pointed out the major limitations of the NPVat-risk method, as follows:

If NPV is calculated using an appropriate risk adjusted discount, any further adjustment for risk is double-counting. If a risk-free rate of interest is used instead, then one obtains a distribution of what the project's value would be tomorrow if all uncertainty about the project's cash flows were resolved between today and tomorrow. But since uncertainty is not resolved in this way, the meaning of the distribution is unclear.

Note that the NPV method and most traditional evaluation tools tend to ignore the "strategic" value of a risky technology investment and help little in evaluating a complex or strategic investment. For example, if the investment can create a managerial flexibility to expand future business territory when the technology is successful and market conditions are good, the NPV method will fail to evaluate the additional value brought by the potential future growth. Other managerial flexibilities that may interact with future uncertainties include the flexibility to expand or contract a project, the option to delay an investment, and the option to speed up or hold up an investment. Researchers in modern financial theory tend to agree that option pricing theory is one of the most promising approaches to addressing such complex investment issues. In infrastructure privatization investment, Ho and Liu (2002) have developed a model on the basis of option pricing theory for evaluating the financial viability of privatized infrastructure projects.

Many emerging A/E/C technology investments are of strategic importance and may create future growth opportunities. Therefore, from the strategic perspective, management needs a better method that can quantify the strategic value of technology investment and suggest optimal investment strategies when the future is uncertain. For example, managers would like to know, When is the right time to invest-now or later? Should they adopt a certain technology that might seem to have "negative" NPV in the early stage? What is the value of the technology investment opportunity? A quantitative model based on the modern option pricing theory in finance will be presented to address these questions.

\section{Option Pricing Theory}

The option pricing theory recognizes the interactions among option holders' optimizing behavior, asset uncertainty, and market disciplines. Recently, the option pricing theory has been applied in the evaluation of nonfinancial assets or "real" investments; researchers also called it "real options." This dynamic pricing process overcomes difficulties in the "discounting approach" such as the NPV method, and computes the value of a strategic investment more realistically. However, to transform the option pricing theory to the evaluation of technology investment is nontrivial. We shall begin by introducing the option pricing theory, and we will then apply the option pricing theory to derive a model that can resolve the difficulties of evaluating the technology investments in $\mathrm{A} / \mathrm{E} / \mathrm{C}$ industries. Moreover, we shall integrate our model with the technology investment process so that the model can cope with various technology characteristics.

A "European call option" is a type of contract giving the right to buy a specific asset, such as a common stock, at a specific price on a specific data in the future. An example could be a three month IBM stock call option. If today is September 20, this call option may specify that the option issuer gives the holder the right to buy an IBM stock from the issuer at the exercise price, e.g., $\$ 120$, on the maturity date, December 20. Therefore, on December 20 the option holder must decide whether to buy an IBM stock at $\$ 120$ or not. If the stock price of IBM is greater than $\$ 120$ on December 20, e.g., $\$ 150$, the option holder will certainly "exercise" his/her option-i.e., to buy an IBM stock and make $\$ 30$ profit. If the stock price is $\$ 110$, the option holder will abandon his/her option and make $\$ 0$ profit. The questions are how to set a price for this stock option, and how the European option price is related to the technology investment evaluation.

Another type of option is called "American options." The American style option allows the holder to exercise the option before its maturity date. Therefore, an American call option on IBM allows the holder to buy an IBM stock at $\$ 120$ on any day before December 20. It can be proved that under certain conditions even when the stock price rises above $\$ 120$, it may not be optimal to exercise the option immediately. For example, if on October 20 the stock price is $\$ 121$, it may not be optimal to exercise the option immediately and earn only $\$ 1$ profit. The holder should probably wait and keep the option alive. It turns out that the problem of "when" to optimally exercise an American option has to be solved simultaneously with the "price" of the option. Traditional asset pricing models cannot resolve this type of dynamic pricing problem for stock options, and the problem has remained for several decades.

Since Black and Scholes (1973) and Merton's (1973b) breakthrough in the valuation of stock options, theories regarding the asset valuation concept and process have advanced into a new era. The basic concept in solving a fair price that is consistent with the capital market is the "no arbitrage opportunity" argument in economics. The argument says that if the asset is mispriced, arbitrage transactions will occur immediately and these transactions will adjust and change the prices until the market equilibrium or a fair price is reached and there exists no arbitrage opportunity. The most powerful feature of this pricing concept is that the price can be solved independent of an individual investor's risk attitude and consistent with the capital market's valuation. In this paper, the option pricing methodology shall be applied to the evaluation of the emerging $\mathrm{A} / \mathrm{E} / \mathrm{C}$ technologies.

\section{Evaluation Model for Single-stage Technology Investment}

A single-stage technology investment involves only one major investment outlay, and the investment is completed soon after the capital is committed. For instance, an adoption of a mature and well-documented 3D computer-aided design technology for detailing that requires only one major capital expenditure at the time of acquiring the system can be considered a single-stage technology investment. For the single-stage technology adoption, the risk that management worries about most is the actual benefit that the new technology can bring. There are two reasons for the risk of the future benefit. First, the benefit can be affected by the imple- 
mentation process. Second, the benefit is contingent on the future market conditions faced by the A/E/C firms. For example, a $\$ 4$ million technology investment may be expected to create $\$ 10$ million future benefit when the future construction market conditions are good, or only $\$ 2$ million future benefit when the market conditions become bad. For simplification, we shall assume that in a single-stage investment, the technology is mature and the implementation is rather straightforward, and that the major investment risk rests in the uncertainty of the future benefit, instead of the investment cost.

\section{Analogy to American Options}

Typical capital budgeting tools evaluate a project by computing its NPV, and the NPV is on the "invest now or never" basis. However, it can be shown that under uncertainty, if the management has options to "invest later," the NPV method cannot evaluate the value of an investment opportunity correctly. In fact, to invest immediately may not be the optimal decision, even when the NPV is positive. If the management has the option to "wait and delay the investment," i.e., to let the uncertainty unfold and make decisions according to the updated information, the value of the investment will be different from the value based on the invest now or never situation. In a mature capital market, such as the United States, with many A/E/C firms that invest in new technologies, the decision in technology adoption is similar to the decision in exercising an American option. This American option feature can be named the "timing option," and it is the most important managerial option embedded in a single-stage investment.

For example, suppose that a new innovative technology requires a fixed cost of $\$ 20$ million, and the management can make the investment on any day before December 20. If today, October 20 , the management's estimate of the expected benefit is $\$ 21$ million in today's price, then the management's questions are to invest today or to wait/delay, and how to compute the value of the investment opportunity. The investment problems here are analogous to the American option pricing problems. First, the investment needs a fixed cost of $\$ 20$ million. The fixed cost is analogous to the exercise price of a stock option. Should the investment be made today, the present value of the estimated benefit is $\$ 21$ million. The future benefit corresponds to the stock price of a stock option and the investment decision is similar to the exercise decision of an American option. Second, management can delay the decision, while the expected benefit is uncertain in the future. Therefore, the holder of an American stock option with an exercise price of $\$ 20$ million and stock price of $\$ 21$ million may want to delay the exercise, instead of realizing his/her profit of only $\$ 1$ million. Note that the expected benefit is risky mainly due to the uncertain future market conditions. The risky benefit is analogous to the risky stock price for a stock option, since the stock price will change due to the uncertainty in the market. As a result, similar to American options, the optimal investment timing and the value of the investment opportunity can be solved altogether.

\section{Valuation of European and American Options, and Single-stage Investments}

Cox et al. (1979) developed an equivalent but more intuitive approach in pricing options based on the fundamental principles drawn by Black and Scholes (1973) and Merton (1973b). In contrast to the option price formula by Black and Scholes (1973), Cox et al.'s framework is a numerical scheme. However, whereas Black and Scholes' analytical formula can be applied only to a

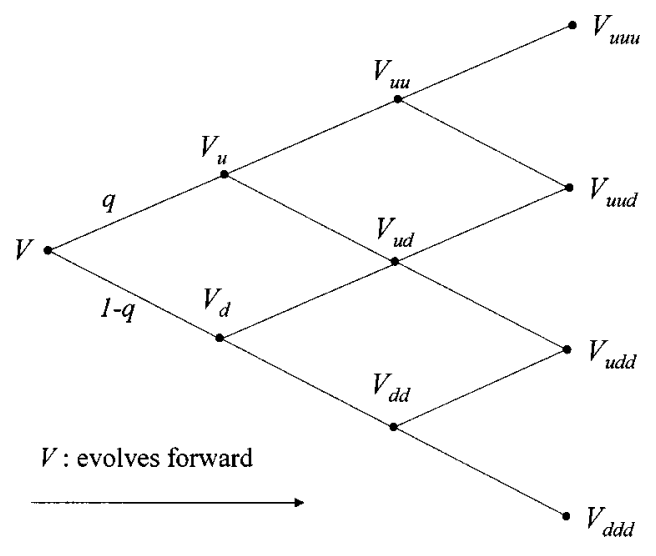

Fig. 1. Binomial tree of $V$ 's distribution

very simple option pricing problem with many restrictions, Cox et al.'s numerical method can solve a more complex and realistic option pricing problem. Another advantage of Cox et al.'s approach is that their approach can be used to show the general concept of how to solve the option value and how the decision process of a single-stage investment is related to American options.

Cox et al.'s (1979) approach is also called the "binomial approach." Given a specific distribution of the asset price in the future, one can transform the distribution into a binomial tree that represents the possible future realizations of asset prices. The binomial tree is shown in Fig. 1, where $V$ is the stock price or the expected benefit of an investment. For illustrative purposes, we divided the three months into only three periods, whereas in actual implementation, the tree will be divided into many periods such that the duration of each period is a small time interval. Here it is assumed that after each period, the stock price can either go up by a certain percentage, $u$, e.g., $120 \%$, or go down by $d$ $=1 / u=1 /(120 \%)=83.3 \%$ with the probability of $q$ and $1-q$, respectively. For example, the $V_{\text {uиd }}$ in Fig. 1 represents that $V$ goes up at Months 1 and 2, and down at Month 3. Note that the probability, $q$, is not the asset's actual probability, since the no arbitrage requirement transforms the actual probability into another pseudoprobability. Typically, in the binomial approach the jump probability, $q$, will remain constant throughout the whole period as long as the asset's volatility or variability stays constant before the option expires. Readers who are interested in the derivation of the binomial tree technique may refer to Cox et al. (1979) or Hull (1997).

In calculating European options, we need to perform the calculation as shown in Fig. 2, where $F$ is the value of the option or technology investment opportunity. Fig. 2 shows that the option price is solved backward recursively starting from the maturity date. First, the option price is $\max [0, V-K]$ at maturity, where $K$ is the exercise price or the cost of a new technology. At Month 2, the option value at each node is obtained by computing the discounted expected Month 3 option value, e.g., $F_{\text {ии }}=\left[q F_{\text {иии }}\right.$ $\left.+(1-q) F_{\text {uиd }}\right] / R$, where $R$ is the discounting factor. Solving backward recursively until Time $0, F$ can be obtained.

As argued earlier, the single-stage investment problem is analogous to the American option problem. In Cox et al.'s (1979) model, the American options can be solved similar to the European options, with an additional consideration of the "exercise or not" decision at each node. This is equivalent to the "stochastic dynamic programming" plus the no arbitrage principle. In American options, one needs to perform the calculation shown in Fig. 2. 




Fig. 2. Binomial tree for solving option value

The Month 3 calculation is the same as in European options. However, the Month 2 calculation involves the comparison between the discounted Month 3 expected option price and the early exercise profit at Month 2. If the early exercise payoff $V_{\text {month2 }}$ $-K$ is greater than $F_{\text {month2 }}$, then one should exercise or invest at Month 2; otherwise, one should keep the option alive and wait until Month 3. For instance, as shown in Fig. 2, the option price when $V=V_{\text {uи }}$ is $F_{\text {uи }}=\max \left\{V_{\text {иu }}-K\left[q F_{\text {uии }}+(1-q) F_{\text {uиd }}\right] / R\right\}$. The tree in Fig. 2 for American options becomes a "decision and valuation tree." Fig. 3 shows the option price curve of an American option with an exercise price of $\$ 120$, where the dashed line is the payoff function at maturity or upon exercise, $\max [0, V$ $-120]$, and $V^{*}$ is the price when the early exercise is optimal. For any $V<V^{*}$, one should not exercise the option immediately.

\section{Three-step Technology Investment Model for Single-stage Technology Investment}

Taking the analogy between the American call option and the emerging $\mathrm{A} / \mathrm{E} / \mathrm{C}$ technology investment, an option pricing based Three-step Technology Investment Model (TSTIM) was developed as follows.

Step 1 is to select the technology risk variables and determine their dynamics and current values. A technology risk variable is defined as an uncertain variable that determines the contingent payoff of a technology investment. In other words, a technology risk variable is a major risky factor that determines the option payoff. In a single-stage emerging technology investment, the future benefit of the technology investment can be considered the major risk variable according to the analogy drawn previously.



Fig. 3. American option value curve and exercise timing
The assumptions made by Majd and Pindyck (1987), Dixit and Pindyck (1994), and Schwartz and Moon (2000) regarding the dynamics of the investment's future benefit are typical in real options analysis, and shall be applied in the model. They assumed that the future benefit evolves according to a lognormal process, or geometric Brownian motion

$$
\frac{d V_{t}}{V_{t}}=\left(\mu_{V}-\delta_{V}\right) d t+\sigma_{V} d w_{V}
$$

where $V_{t}=$ present value of the future benefit or expected cash flows resulting from a technology investment if the technology is implemented at $t ; \mu_{V}=$ market equilibrium rate of return of a completed and traded project; $\sigma_{V}$ represents the volatility of future benefit; $\delta_{V}=$ "rate of return shortfall" of a nontraded project; and $d w_{V}=$ "increment to a standard Wiener process" (Dixit and Pindyck 1994), which is normally distributed with a mean of 0 and a variance of $d t$. The definition of rate of return shortfall will be given in Step 2. Note that $\left(\mu_{V}-\delta_{V}\right)$ and $\sigma_{V}$ are also known as the asset's "drift" and "volatility," respectively; they are considered as the characteristics of a specific technology investment, and thus are assumed to be constant over time. Terms $\mu_{V}$ and $\sigma_{V}$ may be estimated from the observable data in the capital market and from the technology and industry related characteristics. Mathematically, Eq. (1) implies that in an extremely short time interval, the logarithm of $V_{t}$ is normally distributed with the mean, $\left(\mu_{V}-\delta_{V}-\sigma_{V}^{2} / 2\right) d t$, and variance, $\sigma_{V}^{2} d t$. In other words, Eq. (1) implies that $V_{t}$ is lognormally distributed. Eq. (1) also shows that the degree of the uncertainty of $V_{t}$ depends on how far into the future one looks. It is widely recognized that the price distribution of most stocks is actually quite close to lognormal (Luenberger 1998). This distribution has also been broadly adopted by both researchers and practitioners in modeling the values of risky physical assets, such as an oil reserve or a start-up venture. In a single-stage investment, it is assumed that the technology investment cost, $K$, is constant, since the major capital expenditure is incurred at the beginning and there is no further major expenditure. Note that this assumption can be relaxed in a more general setting.

Step 2 is to align the dynamics of the risk variable with the capital market and investment's characteristics. This is a critical step when the underlying asset, $V$, is not a traded security. In the emerging technology investment, the future benefit of an investment cannot be directly traded in the financial market. Therefore, to align the dynamics of $V$, it is assumed that there exists a traded financial asset, e.g., a stock, with the same risk term $\sigma_{V} d w_{V}$. Then one may obtain the asset's market equilibrium rate of return commensurate with the asset's risk characteristic, $\sigma_{V}$, according to Merton (1973a). Let $\mu_{V}$ denote the market equilibrium rate of return, and we have

$$
\mu_{V}=r+\lambda \rho_{V m} \sigma_{V}
$$

where $r=$ risk-free interest rate; $\lambda=$ unit risk premium; and $\rho_{V m}$ $=$ correlation coefficient between the return of $V$ and the average return of the capital market. The concept underlying Eq. (2) is the so-called Capital Asset Pricing Model. The term $\lambda \rho_{V m} \sigma_{V}$ is the risk premium required by investors due to the asset's correlation to the market. This type of risk that deserves a risk premium is the so called "nondiversifiable risk" or "systematic risk." In other words, $\mu_{V}$ is the return rate required by the investors in the capital market for bearing the systematic risk. After $\mu_{V}$ is determined, one needs to determine $\delta_{V}$, the rate of return shortfall. To define $\delta_{V}$, one needs to differentiate the market equilibrium rate of return of a financial asset, $\mu_{V}$, from the rate of return of a non- 
traded asset, $\mu_{V r}$, where the subscript of $\mu_{V r}$ represents the real or physical asset as opposed to the financial asset. Since the nontraded asset is not traded in the capital market, the market does not have an equilibrium or required return on the asset. Nevertheless, the value of the nontraded asset may change as time passes, and the change of value is considered the return of the nontraded asset. For example, if a house of $\$ 200,000$ current value may be expected to grow to $\$ 210,000$ after one year, then the expected rate of return or growth rate on the house is $\mu_{V r}$ $=\$ 10,000 / \$ 200,000=5 \%$ per annum. Note that since in technology investment the nontraded asset is the expected future benefit of an uncommitted project, the growth rate $\mu_{V r}$ can be assumed to be zero in real terms unless the future benefit of the uncommitted project has certain tendencies of growing or shrinking over time. For example, if many competing firms are expected to make the same technology adoption in the near future, then the benefit of technology investment may shrink if the investment is delayed. In this case, $\mu_{V r}$ can be a negative rate. Here $\mu_{V r}$ is inferred by analyzing the competition from competitors. One may consider that $\mu_{V r}$ is determined by the characteristics of a technology investment. According to our prior definition, $\delta_{V}$ can then be obtained and expressed by

$$
\delta_{V}=\mu_{V}-\mu_{V r}
$$

Eq. (3) is the definition of a real asset's rate of return shortfall. By Eq. (3), $\delta_{V}$ is determined by the capital market's observable opinions, $\mu_{V}$, and the characteristics of the investment, $\mu_{V r}$. When the real asset is a project or investment waiting to be undertaken, the rate of return shortfall may represent the opportunity cost of delaying the undertaking of the investment or the profit forgone due to delaying the investment (Dixit and Pindyck 1994). The investment timing will be resolved by balancing the opportunity cost of delaying the investment and the benefit from waiting for the uncertainty to unfold.

Step 3 is to compute the value of the technology investment that contains the timing option. Cox et al.'s binomial approach is suitable for obtaining the optimal investment timing and the technology investment value. However, since McDonald and Siegel (1986) show that the value of a "perpetual American option" could be solved analytically, we shall use McDonald and Siegel's analytical solutions in Step 3 for clarity of the model and ease of the sensitivity analysis. For more complex problems where no analytical solution is available, one should use Cox et al.'s method in Step 3. Note that a perpetual option is an option that will never expire; the technology investment decision can be considered as a perpetual option problem. By fixing the investment cost K, McDonald and Siegel's (1986) solution can be reorganized to evaluate a single-stage technology investment

$$
\begin{gathered}
F(V ; K)=\left(V^{*}-K\right)\left(\frac{V}{V^{*}}\right)^{\beta} \text { when } V \leqslant V^{*} \\
F(V ; K)=V-K \quad \text { when } V>V^{*}
\end{gathered}
$$

where $F=$ value of the investment opportunity

$$
\begin{gathered}
V^{*}=K\left(\frac{\beta}{\beta-1}\right) \\
\beta \equiv\left(\frac{1}{2}-\frac{r-\delta_{V}}{\sigma_{V}^{2}}\right)+\sqrt{\left(\frac{r-\delta_{V}}{\sigma_{V}^{2}}-\frac{1}{2}\right)^{2}+2 r / \sigma_{V}^{2}}
\end{gathered}
$$

Eq. (5) can be rewritten as

$$
C^{*}=\frac{V^{*}}{K}=\frac{\beta}{\beta-1}
$$

where $C^{*}=$ critical ratio for the investment to be undertaken without waiting; hence, $V^{*}=$ investment threshold. Note that from Eqs. (4)-(6), we know that although the investment is risky, the value of the investment opportunity does not depend on any parameters determined by the investor's risk attitude. In an efficient capital market, the investors, as the stockholders and owners of $\mathrm{A} / \mathrm{E} / \mathrm{C}$ firms, will compel management's investment valuation process to be consistent with the market disciplines.

\section{Illustrative Example of Single-stage Investment}

SmartArch Inc. is an architecture firm. The management is evaluating the investment of a Virtual Reality Walkthrough System that can significantly improve and promote their design. The technology needs $\$ 1$ million of capital expenditure. Suppose that SmartArch estimates that the virtual reality system can increase the number of yearly winning bids by a certain percentage for the next seven years. Future benefit resulting from the investment is assessed by the yearly net cash flow increase due to the saved cost and the increase of winning bids. Suppose that the estimated yearly net cash flow increases for Years 1 through 7 are $\$ 0.15$ million, \$0.2 million, \$0.3 million, \$0.3 million, \$0.4 million, \$0.4 million, and \$0.2 million, respectively. However, SmartArch is aware that the actual benefit will be materially affected by the change in competition and economic conditions. The discount rate used to obtain the present value is the weighted average cost of capital (WACC) of the firm, 15\%. Should SmartArch invest right away? What is the value of the technology investment opportunity?

First, we may compute the present value of the future benefit according to the estimated yearly net cash flow increases, and then obtain $V=\$ 1.1$ million. The investment has $\$ 1.1-1.0$ $=\$ 0.1$ million NPV, and according to the NPV method SmartArch should invest right away. We now consider the option to delay or wait. To perform the TSTIM analysis for single-stage investment, we need to model the risk and estimate the parameters as shown in Steps 1 and 2. Suppose that these estimates are $r=0.05, \mu_{V r}=0, \sigma_{V}=0.25, \lambda=0.35, \rho_{V m}=0.8, \mu_{V}=0.12$ by Eq. (2), and $\delta_{V}=0.12$ by Eq. (3). Note that $\sigma_{V}=0.25$ can be estimated from the volatility of the stock prices of several architecture firms that have similar business risks. Details regarding the volatility estimation can be found in Hull (1997). Ideally, these architecture firms should have a history or reputation of emphasizing the technology leadership among the competitors. In Step 3 , we may compute the value of the information technology investment according to Eq. (4), and obtain the value $F$ $=\$ 0.165$ million. Note that by computing Eqs. (6) and (7) in Step 3 , we may obtain $C^{*}=1.37$; i.e., $V^{*}=1.37 K=\$ 1.37$ million. Since the expected future benefit, $V=\$ 1.1$ million, is less than the investment threshold, SmartArch should delay the investment until the expected future benefit reaches the threshold, $\$ 1.37$ million. According to Eq. (4), when $V$ equals $\$ 1.1$ million, the value of the investment opportunity is $\$ 0.165$ million, instead of the NPV value of $\$ 0.1$ million. So, the value of the timing option is $\$ 0.165-0.1=\$ 0.065$ million; in other words, by delaying the investment, SmartArch gains an additional \$0.065 million toward the investment opportunity.

We may also perform a sensitivity analysis to analyze the impacts of the volatility of $V$. Fig. 4 shows the value of the investment opportunities with respect to different $\sigma_{V}$. The solid line curve represents our base case given earlier. The short-dashed line 


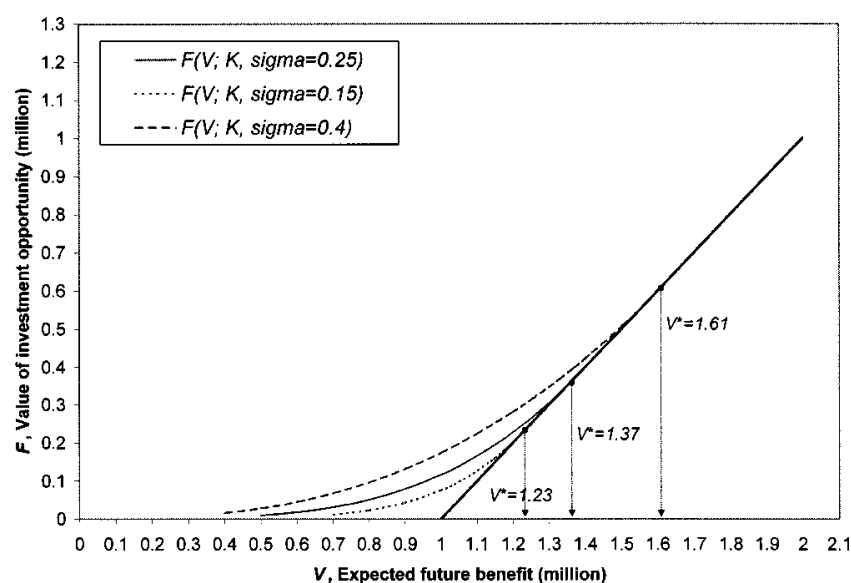

Fig. 4. Investment timing and value of investment opportunity under various volatilities, $\sigma_{V}$

shows that when $V$ is less volatile with $\sigma_{V}=0.15$, SmartArch should invest earlier when $V$ reaches $\$ 1.23$ million. Note that $\mu_{V}$ and $\delta_{V}$ should be recomputed according to Eqs. (2) and (3), respectively, when the volatility of $V$ changes. Here we have $\mu_{V}$ $=0.09$ and $\delta_{V}=0.09$ when $\sigma_{V}=0.15$. The long-dashed line shows that if the future benefit is highly volatile with $\sigma_{V}=0.4$, SmartArch should wait until $V$ reaches $\$ 1.61$ million to justify an immediate investment. Note that with this high volatility, when $V$ equals \$1.1 million, Eq. (4) gives the value of the investment opportunity, $\$ 0.223$ million, and this value is significantly greater than $\$ 0.165$ million, the investment value with a lower volatility of $\sigma_{V}=0.25$. Fig. 4 shows this counterintuitive finding: Higher technology risk, $\sigma_{V}$, may induce higher value toward the investment. This finding suggests that risky emerging technology investment is valuable, but should not be invested too early.

Note that the analysis shown in Fig. 4 assumes that there is no technology competition. To complicate the technology investment situations, suppose that SmartArch is facing an intensive technology competition in the market such that the benefit from the technology investment will shrink by $30 \%$ per year if the investment is delayed. The benefit shrinkage is mainly because of the loss of competitive advantages due to the competitors' early investment in the same or similar technology. In this case, it can be estimated that $\mu_{V r}=-0.3$ due to the benefit shrinkage over time; consequently, $\delta_{V}=\mu_{V}-\mu_{V r}=0.42$. Here this type of competition can be called the "investment competition." By Eq. (5), SmartArch should undertake the investment as soon as $V$ reaches $\$ 1.08$ million. However, if the investment competition is not intensive, e.g., $\mu_{V r}=-0.1$, SmartArch should wait until $V$ reaches $\$ 1.17$ million. Our base case, $\mu_{V r}=0$, could represent that SmartArch faces no investment competition or owns the patent to the technology. Fig. 5 shows the value of the technology investment opportunity with respect to various technology competition intensities.

\section{Single-stage Investment Strategies}

Compared to the conventional "invest when the NPV is positive" rule, the option pricing theory based TSTIM provides a richer technology investment strategy profile. For example, with greater volatility of $V$ and less investment competition, the management should make the investment at a higher threshold, and vice versa. Our analysis also explains why sometimes management hesitates to adopt new technologies even when a specific technology has shown positive NPV. In summary, low technology competition

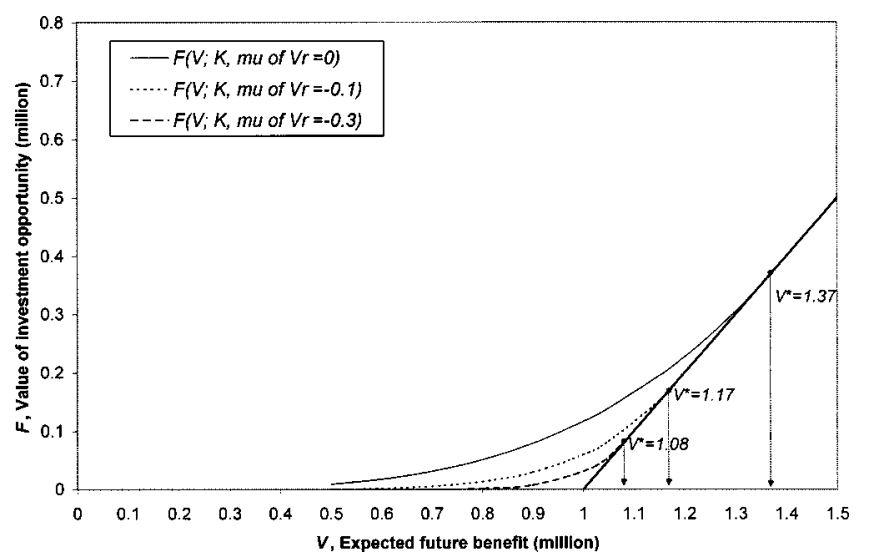

Fig. 5. Investment timing and value of investment opportunity under various technology competition intensities, $\mu_{V r}$

and a risky business environment in the construction industry contribute to the delay of emerging $\mathrm{A} / \mathrm{E} / \mathrm{C}$ technology investment. Note that to delay an investment is by no means to abandon an investment; instead, the management should keep monitoring those investment opportunities that have positive NPVs.

\section{Evaluation Model for Multistage Technology Investment}

A multistage investment has at least two stages of investment, and each stage has one major investment outlay. Many emerging $\mathrm{A} / \mathrm{E} / \mathrm{C}$ technologies are of this type. For example, construction robotics development may include several years of R\&D activities before any practical applications. Many information technology investments may also require periodic system upgrades, and each major system upgrade may incur a major capital outlay. For some firms, the technology adoption process may take several stages, depending on the scale or number of subsidiaries of the firms. In some cases, the adoption process gradually evolves from a small scale or project level implementation to a full scale or firm level implementation.

\section{Option to Stop or Continue}

One of the most important managerial options or flexibilities embedded in a multistage technology adoption is the option to "quit" or "continue" after each stage. In other words, management can decide to quite in the next stage, if either the outcome from the previous phase or the market situation turns out to be disadvantageous. In typical capital budgeting techniques, decision makers will discount and sum up the expected cost incurred in each phase, and compare it with the present value of the expected future payoff. The option to stop or continue at the end of each stage is ignored in the traditional evaluation process. Even if one tries to use the decision tree-like technique to consider the managerial option, it is very difficult to determine an appropriate discount rate in the changing risk profile when there exist various managerial flexibilities at each stage. Option pricing theory can be used to account for the managerial flexibilities and align the value of the investment with the capital market disciplines. For simplicity, we shall demonstrate the valuation and investment strategies of a two-stage investment without considering its timing or waiting option at the end of each stage, although more 
complex or numerical models can be developed based on the same set of principles to cope with the timing options embedded in each stage.

\section{Three-step Technology Investment Model for Multistage Technology Investment}

Suppose that an emerging technology is still at the R\&D stage, the investment requires $K_{1}$ initial investment outlay, and it will take $\tau$ years to complete R\&D. At year $\tau+1$, the second stage, the company will start implementing the technology. Suppose the expected investment outlay in the second stage is $K_{2}$ and the present value of the expected payoff from the technology investment is $V_{\tau+1}$. At year $\tau+1$, the investment will be continued if $V_{\tau+1}$ $\geqslant K_{2}$, or stopped if $V_{\tau+1}<K_{2}$. As a result, the payoff function at $\tau+1$ is $\max \left[0, V_{\tau+1}-K_{2}\right]$. Again, we assume that $V$ follows a geometric Brownian motion as shown in Eq. (1). If $K_{2}$ is a constant, then the value of the option to invest in the second stage can be evaluated by the value of a European call option. However, in this paper we shall consider a more realistic and complex situation, and assume that $K_{2}$ is also uncertain and follows the geometric Brownian motion. The major reason is that the multistage technology investment may involve significant "technical related uncertainty" that can only be resolved or revealed after the implementation of the previous stage. For example, after R\&D activities, a more accurate amount of second stage investment outlay may be revealed.

Similarly, a three-step evaluation method can be developed for a multistage technology investment. The tasks in each step are identical to the tasks described in the single-stage investment. The only differences are the dynamics of the risk variables and the option pricing formula.

In Step 1, two technology risk variables, instead of one, are selected. The first risk variable is the expected future benefit due to the emerging technology adoption. The second risk variable is the second stage investment outlay, $K_{2}$. One may follow the typical assumption used in the literature that the dynamics of $K_{2}$ follow

$$
\begin{gathered}
\frac{d K_{2, t}}{K_{2, t}}=\left(\mu_{K_{2}}-\delta_{K_{2}}\right) d t+\sigma_{K_{2}} d w_{K_{2}} \\
\mu_{K_{2}}=r+\lambda \rho_{K_{2} m} \sigma_{K_{2}} \\
\rho_{K_{2} m}=\rho_{V K_{2}}=0
\end{gathered}
$$

The notations in Eq. (8) are similar to those in Eq. (1). Equations (1) and (8) give the dynamics of the two risk variables. Here, $\mu_{K_{2}}=$ market equilibrium return rate for $K_{2}$; and $\rho_{K_{2} m}$ $=$ correlation coefficient between the return of $V$ and the return of the market. We use $\rho_{K_{2} m}=0$ to explicitly assume that the uncertainty of $K_{2}$ is purely technical; i.e., it has no correlation with the economic conditions. As a result, from Eq. (9) and (10), we have $\mu_{K_{2}}=r+0=r$. This means that a well-diversified investor will not pay a risk premium for the risk of $K_{2}$, because the risk is uncorrelated with the capital market and can be diversified away. Note that $\rho_{K_{2} m}=0$ also implies $\rho_{V K_{2}}=0$, as shown in Eq. (10). Yet, the assumption made in Eq. (10) may be relaxed for more general cases.

In Step 2, the parameters in Eqs. (1) and (8) are estimated. The rate of return shortfall of each risk variable is determined. These estimations ensure that the valuation process aligns the value of the multistage investment with the capital market and the technology characteristics.
In Step 3, we shall compute the value of the complex option due to the additional risk variable. With two risk variables, the option becomes a European exchange option - an option to exchange one risky asset for another risky asset at the maturity date. Note that Cox et al.'s (1979) method can be extended to cope with the options with two risk variables. Also, under certain conditions, McDonald and Siegel (1985) have developed an analytical solution for this type of option, which is equivalent to the solution by Cox et al.'s approach. McDonald and Siegel (1985) show that the value of a European exchange option is

$$
\begin{aligned}
s\left(V, K_{2}, \tau\right)= & V e^{-\delta_{V} \tau} N_{1}\left(d_{1}\left(\frac{V}{K_{2}} e^{-\delta \tau}\right)\right) \\
& -K_{2} e^{-\delta_{K_{2}} \tau} N_{1}\left(d_{2}\left(\frac{V}{K_{2}} e^{-\delta \tau}\right)\right)
\end{aligned}
$$

where $N_{1}(d) \equiv \int_{-\infty}^{d} e^{-z^{2} / 2} / \sqrt{2 \pi} d z=$ univariate standard normal distribution function; $\quad d_{1}\left(\left(V / K_{2}\right) e^{-\delta \tau}\right) \equiv \ln \left(V / K_{2} e^{-\delta \tau}\right)$ $+\sigma^{2} \tau / \sqrt{\sigma^{2} \tau} ; \quad \delta \equiv \delta_{V}-\delta_{K_{2}} ; \quad \sigma^{2} \equiv \sigma_{V}^{2}+\sigma_{K_{2}}^{2}-2 \rho_{V K_{2}} \sigma_{V} \sigma_{K_{2}}$ $=$ variance rate of $d\left(V / K_{2}\right) /\left(V / K_{2}\right) ;$ and $d_{2}\left(\left(V / K_{2}\right) e^{-\delta \tau}\right)$ $\equiv d_{1}\left(\left(V / K_{2}\right) e^{-\delta \tau}\right)-\sigma \sqrt{\tau}$.

The two-stage investment opportunity can be considered as buying an exchange option by paying $K_{1}$. Therefore, if $s\left(V, K_{2}, \tau\right) \geqslant K_{1}$, i.e., the value of the exchange option is greater than the cost of the exchange option, then the investment should be undertaken; otherwise, it should be rejected. Note that, in fact, at the second stage the decision maker has a third option, to wait. The numerical method is needed to solve problems with the third option. However, the basic principles behind the numerical method are the same as those described for the single-stage investment. For simplicity, we shall not consider the waiting option at the end of the first stage.

Note that the previous two-stage implementation is just a special case of multistage investments. A general multistage investment can be treated as a "compound option," an option on another option on another, and so on. The solution to this general multistage technology adoption can be solved by numerical methods, such as Cox et al.'s binomial tree approach.

\section{Illustrative Example of Multistage Investment}

Suppose that GrowthCon Inc., an international construction firm, is evaluating an integrated intelligent database and decision support system that requires several stages of implementation. The investment includes the first stage of a three-year system analysis and prototype development and the second stage of full scale implementation. The first stage requires a fixed cost of $K_{1}$ $=\$ 4$ million at time 0 prices. Suppose that due to the technical uncertainty, the actual cost for the second stage at the beginning of Year $4, K_{2}$, can be known only after the first stage; yet it can be estimated and the expected cost at Year 4 prices is $K_{2}$ $=\$ 10$ million. The intelligent database and decision support system will help GrowthCon compete with other major international firms and expand the global market shares. However, the actual benefit is uncertain and depends on the global construction market conditions. The current estimate of the overall expected benefit at the beginning of Year 4 prices is $\$ 17$ million. After the first stage is completed, if the cost of the second stage exceeds the future profit estimated at the completion of the first stage, the second stage implementation can be forgone. Should GrowthCon invest now or not? What is the value of the investment opportunity?

In the NPV approach, the value of the "contingent" investment is very difficult to assess. Although the decision tree analy- 
sis can be used for contingent future investment, the determination of the discount rate of each scenario is difficult and subjective, especially when there are more than one risk variable. Here we shall show how our option pricing based model can be used to evaluate the technology investment with the contingent investment.

Note that $K_{2}$ shall be discounted by $\mu_{K_{2}}$, which equals $r+0$ $=r$ by Eqs. (9) and (10), and $V$ shall be discounted by $\mu_{V}$ $=0.12$. In this case, the net present value of the second stage investment is $P V(V)-P V\left(K_{2}\right)=\$ 17$ million $/ 1.12^{3}$ $-\$ 10$ million $/ 1.05^{3}=\$ 3.46$ million. Compared to the first stage investment cost, $\$ 4$ million, according to the NPV method, GrowthCon should not undertake this two-stage investment. It is obvious that the option to stop or continue at the end of the first stage is not considered by the NPV method. We now consider the option to stop or continue at the end of the first stage by following the three-step valuation model. The risk factors and their dynamics are determined in the first two steps. Suppose that the expected benefit follows Eq. (1) with $\mu_{V r}=0$ and $\sigma_{V}=0.25$, and the cost of the second stage follows Eq. (8) with $\mu_{K_{2} r}=0$ and $\sigma_{K_{2}}$ $=0.2$. Other estimates include $\mu_{V}=0.12, \mu_{K_{2}}=r$, and $r=0.05$. In Step 3, we apply the option pricing theory and recompute the value using Eq. (11), and we can obtain the option value $s(\$ 17$ million, $\$ 10$ million, 3$)=\$ 4.21$ million. This is the value of the contingent second stage investment, and this contingent investment is analogous to a European exchange option. In this example, since the value of the second stage investment opportunity is greater than the first stage investment cost, $\$ 4$ million, GrowthCon should adopt the intelligent database and decision support system.

\section{Multistage Investment Strategies and Growth Options}

Kester (1984) shows that "growth options" may "constitute well over half of the market value of many companies' equity." Growth options are the options created by an investment project that makes follow-on investments should market conditions turn out to be advantageous. R\&D projects and many emerging $\mathrm{A} / \mathrm{E} / \mathrm{C}$ technology investments can be regarded as this type of investment that creates growth options. The TSTIM for multistage investment demonstrates its strength in pricing and quantifying the "strategic value" of such investments.

The illustrative example given earlier shows that the option to stop or continue in a two-stage technology adoption is valuable. Thus, if a successful technology development can place a firm in a leading position by creating competitive advantages, then to invest in or implement an "unprofitable" or "risky" premature technology may be justified by considering its future growth opportunities or strategic value. It can also be shown that to divide an investment into several "stoppable stages" is desirable because of the options to abandon and the values of these options.

Sensitivity analysis on the impacts of cost uncertainty can also be conducted for multistage investment. It can be shown that higher technical related cost uncertainty $\sigma_{K_{2}}$ can lead to a higher technology investment value, but a higher $\sigma_{V}$ does not necessarily make an investment more valuable.

\section{Model Verification and Validation}

Various models based on the option pricing theory for evaluating investments have been verified and validated by both known cases from the literature, such as Kemna (1993), and real cases, such as the Channel Tunnel Project (Ho 2001). Their results indicate that these models can represent real-world situations more realistically and provide a more accurate assessment of investment. More detailed discussion on the model verification and validation can be found in Ho (2001).

\section{Conclusions}

Today, A/E/C firms are constantly faced with emerging technologies, such as information technology and automation/robotics, which often involve high risks or uncertainties. The traditional NPV method falls short on its ability to determine the appropriate discount rate under uncertainty and to evaluate the strategic value of an investment. The option pricing based TSTIM presented in this paper provides an alternative, evaluating technology investment more realistically and accurately. On the basis of the option pricing theory, our model incorporates the market disciplines, the technological and market uncertainties, and the managerial strategic options in a unified framework. As a result, the model systematically aligns the investment decision-making process with the characteristics of the capital market and technology investment.

The model can help the A/E/C firms evaluate the technology investment and develop optimal investment strategies. In singlestage investment, where the technology is relatively known and mature, investors can more realistically assess its timing option and associated risks. In multistage investment, where R\&D activities are often involved, companies can more accurately evaluate their risk exposure and the strategic value embedded in each stage, and develop better management and investment strategies with regard to new technologies. The model provides a good alternative to the NPV method when uncertainty is high, and particularly is suitable for emerging technology investment, where the timing, maturity of technology, and strategic planning play critical roles in deciding the financial viability of an investment.

\section{References}

Aggarwal, R. (1993). Capital budgeting under uncertainty: New and advanced perspectives, Prentice-Hall, Englewood Cliffs, N.J.

Black, F., and Scholes, M. (1973). "The pricing of options and corporate liabilities." J. Political Economy, 81, 637-654.

Copeland, T. E., and Weston, J. F. (1988). Financial theory and corporate policy, Addison-Wesley, Reading, Mass.

Cox, J., Ross, S., and Rubinstein, M. (1979). "Option pricing: A simplified approach.” J. Financ. Econ., 7, 229-263.

Dixit, A., and Pindyck, R. (1994). Investment under uncertainty, Princeton University, Princeton, N.J.

Ho, S. P. (2001). "Real options and game theoretic valuation, financing and tendering for investments on build-operate-transfer projects." $\mathrm{PhD}$ thesis, Dept. of Civil and Environmental Engineering, Univ. of Illinois at Urbana-Champaign, Urbana, Ill.

Ho, S. P., and Liu, L. Y. (2002). "An option pricing based model for evaluating the financial viability of privatized infrastructure projects." Constr. Manage. Econom., 20, 143-156.

Hull, J. C. (1997). Options, futures, and other derivatives, 3rd Ed., Prentice-Hall, Upper Saddle River, N.J.

Kemna, A. G. Z. (1993). "Case studies on real options." Financial Management, 22, 259-270.

Kester, W. (1984). “Today's options for tomorrow's growth.” Harvard Bus. Rev., 62, 153-160.

Luenberger, D. (1998). Investment science, Oxford University Press, New York. 
Majd, S., and Pindyck, R. S. (1987). "Time to build, option value, and investment decisions." J. Financ. Econ., 18, 7-27.

McDonald, R., and Siegel, D. (1985). "Investment and the valuation of firms when there is an option to shut down." Int. Econom. Rev., 26(2), 331-349.

McDonald, R., and Siegel, D. (1986). "The value of waiting to invest." Quart. J. Econom., 101, 707-727.

Merton, R. C. (1973a). "An intertemporal capital asset pricing model." Econometrica, 41, 867-887.

Merton, R. C. (1973b). "Theory of rational option pricing." Bell J. Economics and Management Science, 4, 141-183.

Mitropoulos, P., and Tatum, C. B. (1999). "Technology adoption decisions in construction organizations." J. Constr. Eng. Manage., 125(5), 330-338.

Myers, S. C. (1976). "Using simulation for risk analysis." Modern de- velopments in financial management, S. C. Myers, ed., Praeger, Westport, Conn.

Schwartz, E. S., and Moon, M. (2000). "Evaluating research and development investments." Project flexibility, agency, and competitionNew development in the theory and application of real options, M. Brennan and L. Trigeorgis, eds., Oxford University Press, New York.

Trigeorgis, L. (1996). Real options: Managerial flexibility and strategy in resource allocation, MIT Press, Cambridge, Mass.

Warszawski, A., and Navon, R. (1998). "Implementation of robotics in building: Current status and future prospects." J. Constr. Eng. Manage., 124(1), 31-41.

Ye, S., and Tiong, R. L. K. (2000). "NPV-at-risk method in infrastructure project investment evaluation." J. Constr. Eng. Manage., 126(3), $227-233$. 